\title{
Novel antibacterial triterpenoid from Combretum padoides [Combretaceae]
}

\author{
Jeremiah E. Angeh ${ }^{a}$, Xueshi Huang ${ }^{\text {b }}$, Gerry E. Swan ${ }^{a}$, Ute Möllman ${ }^{\text {b }}$, Isabel Sattler , \\ and Jacobus N. Eloff ${ }^{\text {** }}$ \\ ${ }^{a}$ Phytomedicine Programme, Department of Paraclinical Science, Faculty of Veterinary Science, \\ University of Pretoria, Onderstepoort Oaa0, South Africa \\ ${ }^{b}$ Leibniz Institute for Natural Product Research and Infection Biology, Beutenbergstrasse 11a, \\ D-07745 Jena, Germany \\ E-mail: kobus.eloff@up.ac.za
}

\section{Dedicated to Professor Berhanu M. Abegaz on the occasion of his 60th birthday}

\begin{abstract}
The dichloromethane extract of $C$. padoides leaves was subjected to antibacterial activity guided fractionation against Staphylococcus aureus to afford a new oleanene-type triterpenoid glycoside identified as $1 \alpha, 23 \beta$-dihydroxy-12-oleanen-29-oic-acid-23 $\beta$-O- $\alpha-4$-acetylrhamnopyranoside (1) together with two known compounds 1,22-dihydroxy-12-oleanen-30-oic acid (2) and 24ethylcholesta-7,22,25-trien-O- $\beta$-D-glucopyranoside (3) on the basis of 1D NMR, 2D NMR and ESI-MS analysis. Compounds $\mathbf{1}$ and $\mathbf{2}$ had a reasonable antibacterial activity [MIC of 0.031 and $0.063 \mathrm{mg} / \mathrm{ml}$ ] against $S$. aureus and Escherichia coli. All compounds were non-cytotoxic. The results indicate that pentacyclic triterpenes from $C$. padoides have some antibacterial activity with no cytotoxic activity.
\end{abstract}

Keywords: Combretum padoides, Combretaceae, triterpenoid, antibacterial, cytoxicity

\section{Introduction}

In our preliminary screening of members of the Hypocrateroptis section $(C$. imberbe Wawra, $C$. padoides Engl. \& Diels, C. celestroides Welw. ex M. A. Lawson ssp celestroides and $C$. celestroides Welw. ex M. A. Lawson ssp. orientale), several antibacterial compounds were detected in $C$. imberbe and $C$. padoides. These results are in agreement with the antibacterial data obtained earlier. ${ }^{1}$ A TLC survey of the Combretum genus indicated the presence of saponins in the leaves of $C$. padoides Eng. \& Dielbs. ${ }^{2}$ Earlier studies of $C$. padoides leaves led to the isolation of triterpenoid desmosides. ${ }^{3}$ Other studies of the Combretum species resulted in the 
discovery of mollic acid glycosides, anti-inflammatory and antifungal agents from C. molle, ${ }^{4}$ and imberbic acid from $C$. imberbe. ${ }^{5}$ Both types of compounds had been identified as potent molluscides. Substantial chemical work has been done on the extracts of the leaves of $C$. padoides and related species, but little has been reported on their biological activities. Investigation of 27 Combretaceae species revealed that C. padoides had the fifth highest antibacterial activity. ${ }^{1}$ This paper describes the isolation, structure elucidation and some biological activities of a new triterpenoid rhamnoside and two related known compounds from $C$. padoides leaves.

\section{Results and Discussion}

Based on bioautography most of the antibacterial compounds were shown to be present in the DCM fraction. Further solvent/solvent fractionation indicated that the chloroform fraction was the most active (MIC $0.037 \mathrm{mg} / \mathrm{ml}$ ). Exhaustive gradient column chromatography yielded three triterpenoids (1-3).

Compound 1 was isolated as white crystals and its molecular formula of $\mathrm{C}_{38} \mathrm{H}_{60} \mathrm{O}_{10}$ was deduced from molecular ion peak $[\mathrm{M}-\mathrm{H}]^{-}$at $\mathrm{m} / \mathrm{z} 675.4100$ in the HRESIMS (calculated 675.4108).

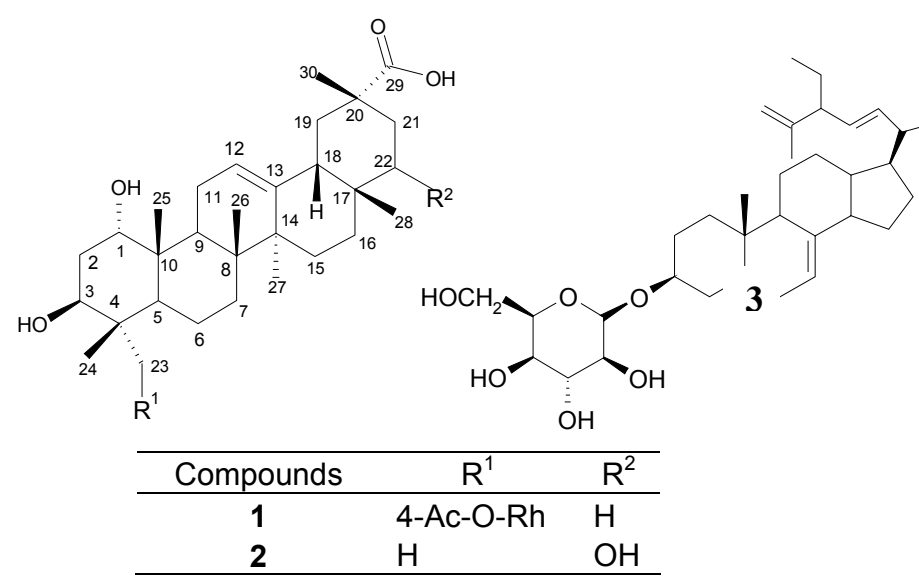

IR analysis indicated the presence of olefinic $\left(1653 \mathrm{~cm}^{-1}\right)$, hydroxyl $\left(3440 \mathrm{~cm}^{-1}\right)$, methyl $\left(1456 \mathrm{~cm}^{-1}\right)$ and carboxylic acid (hydroxyl at $2923 \mathrm{~cm}^{-1}$ and $1772 \mathrm{~cm}^{1}$ ) moieties. The triterpenoid skeleton was easily deduced from ${ }^{1} \mathrm{H}$ NMR data by the appearance of vinylic $\left(\mathrm{R}_{2} \mathrm{C}=\mathrm{CHR}, \delta_{\mathrm{H}}\right.$ 5.24), hydroxylated methine $\left(\mathrm{RCHOH}, \delta_{\mathrm{H}} 3.55\right)$ and acetyl $\left(\mathrm{CH}_{3} \mathrm{COO}-, \delta_{\mathrm{H}} 2.07\right)$ moieties (Table 1). There was also a crowded signal indicating the presence of $-\mathrm{CH}_{3},-\mathrm{CH}_{2}$, and $-\mathrm{CH}$ protons $\left(\delta_{\mathrm{H}}\right.$ $\left.0.5-\delta_{\mathrm{H}} 2.0\right)$. The ${ }^{13} \mathrm{C}$ NMR spectrum confirmed these findings. In addition it showed the typical carboxyl function at $\delta_{\mathrm{c}} 183.1$ of the $-\mathrm{CO}_{2} \mathrm{H}$ constituent. Altogether, eight methyl groups, ten methylenes, eleven methines and nine quaternary carbons were revealed by DEPT data. The ${ }^{1} \mathrm{H}$ 
and ${ }^{13} \mathrm{C}$ NMR data of compound $\mathbf{1}$ were similar to those of $\mathbf{2}$ except for differences in signals of rings $\mathrm{A}$ and E relating to different hydroxylation patterns. In 1, the methyl group at C-23 carries an ether linked substitution as indicated by the new methylene group at $\delta_{\mathrm{C}} 70.3 / \delta_{\mathrm{H}} 3.25 \mathrm{dd}, 3.50$ dd. In ring E, C-22 is a regular methylene and not oxygenated such as that in compound $2\left(\delta_{c}\right.$ 31.1).

According to $\mathrm{HMBC}$, the carboxylic acid carbonyl is located at $\mathrm{C}-20$ and one of the hydroxyl groups is located at $\mathrm{C}-1\left(\delta_{\mathrm{c}} 72.6\right)$ as earlier indicated by HMQC. Assisted by the ${ }^{1} \mathrm{H}-{ }^{1} \mathrm{H}$ COSY, the spin system of the complete rhamnose-skeleton ( $\mathrm{Rh}$ ') was traced. Using HMQC and ${ }^{13} \mathrm{C}$ spectra, the proton appearing as a singlet at $\delta_{\mathrm{H}} 4.69$ was assigned as an anomeric proton of the sugar unit. The proton at $\delta_{\mathrm{H}} 4.93(\mathrm{Rh}$ '-4) was assigned as located next to an acetyl substituent of the sugar moiety. C-23 was unequivocally assigned as the site of glycosylation by a HMBC correlation between $\mathrm{H}-\mathrm{Rh}-1\left(\delta_{\mathrm{H}} 4.69\right)$ and the oxymethylene $\mathrm{C}-23$. This position has been shown as the preferred site of glycosylation in similar compounds from the related $C$. imberbe. ${ }^{5}$

The relative configurations of the chiral centres at C-1, C-3, C-4, C-8, C-10, C-14, C-17, and C-20 were determined by NOESY analysis: correlations between $\mathrm{H}-1\left(\delta_{\mathrm{H}} 3.55\right)$ and $\mathrm{H}-27\left(\delta_{\mathrm{H}}\right.$ $1.26), \mathrm{H}-24\left(\delta_{\mathrm{H}} 0.70\right)$ and $\mathrm{H}-25\left(\delta_{\mathrm{H}} 1.00\right), \mathrm{H}-18\left(\delta_{\mathrm{H}} 2.01\right)$ and $\mathrm{H}-28\left(\delta_{\mathrm{H}} 0.87\right), \mathrm{H}-18\left(\delta_{\mathrm{H}} 2.01\right)$ and H-30 $\left(\delta_{\mathrm{H}} 1.19\right), \mathrm{H}-\mathrm{Rh} '-2\left(\delta_{\mathrm{H}} 3.90\right)$ and H-Rh'-4 $\left(\delta_{\mathrm{H}} 4.93\right), \mathrm{H}-\mathrm{Rh}{ }^{\prime}-1\left(\delta_{\mathrm{H}} 3.55\right)$ and H-Rh'-4 $\left(\delta_{\mathrm{H}}\right.$ 4.93) indicated that these protons are oriented in the same direction. On the other hand, the NOESY correlations between H-23 $\left(\delta_{\mathrm{H}} 3.50\right)$ and H-27 $\left(\delta_{\mathrm{H}} 1.26\right), \mathrm{H}-\mathrm{Rh}$ '-6 $\left(\delta_{\mathrm{H}} 1.13\right)$ and H-Rh'-3 $\left(\delta_{\mathrm{H}} 4.14\right)$ indicated these to be oriented in the opposite direction. According to the coupling constants and correlation peaks in NOESY spectrum, 1 showed the same relative stereochemistry in the triterpenoid skeleton as $1 \alpha, 23 \beta$-dihydroxy-12-oleanen-29-oic acid. For the stereochemistry of the sugar moiety, the signal of the anomeric carbon at $\delta_{c} 101.5$ strongly suggested a $\beta$ orientation of the anomeric proton. Altogether, compound 1 was thus elucidated as $1 \alpha, 23 \beta$ dihydroxy-12-oleanen-29-oic-acid-23 $\beta$-O- $\alpha$-4-acetylrhamnopyranoside. This compound has not been previously reported.

ESIMS analysis of 2 indicated a molecular ion peak at $\mathrm{m} / z 495.8[\mathrm{M}+\mathrm{Na}]^{+}$, suggesting a molecular formula of $\mathrm{C}_{30} \mathrm{H}_{48} \mathrm{O}_{4}$ indicating seven degrees of unsaturation. This structural type was further supported by the ${ }^{1} \mathrm{H}$ and ${ }^{13} \mathrm{C}$ NMR spectra, which included resonances for seven skeletal methyl groups, ten methylene groups, five methyl groups, eight quaternary carbons (from DEPT) and a broad triplet at $\delta_{\mathrm{H}} 5.25$ of an olefinic proton $(\mathrm{H}-12)$, carboxylic acid functionality $\left(\delta_{\mathrm{c}}\right.$ $182.90)$ and two hydroxylated methines $\left(\delta_{\mathrm{H}} 3.6, \delta_{\mathrm{c}}, 74.01\right.$ and $\left.\delta_{\mathrm{H}} 3.75, \delta \mathrm{c} 72.97\right)$. The attribution of ${ }^{1} \mathrm{H},{ }^{13} \mathrm{C}$, DEPT NMR data of compound 2 was in perfect agreement with those of 1,22dihydroxy-12-oleanen-30-oic. ${ }^{6}$ ESIMS of $\mathbf{3}$ that was isolated as greyish powder showed a molecular ion peak $\left[\mathrm{M}+\mathrm{NH}_{4}\right]^{+}$at $\mathrm{m} / z$ 591.0, thus suggesting a molecular formula of $\mathrm{C}_{35} \mathrm{H}_{36} \mathrm{O}_{6}$. Next to typical terpenoid methines and methylenes, its ${ }^{1} \mathrm{H}$ NMR spectrum revealed a sugar moiety, olefenic protons and an acetal proton. Signals for five methyls, eleven methylenes, sixteen methines, and three quaternary carbons were revealed by DEPT NMR data. ${ }^{13} \mathrm{C}$ NMR confirmed all these structural features. The structure of $\mathbf{3}$ was established as 24-ethylcholesta7,22,25-trien-3-ol-O- $\beta$-D-glucopyranoside that has been previously isolated from Clerodendron inerme. ${ }^{7}$. 
Table 1. ${ }^{1} \mathrm{H}(300 \mathrm{MHz})$ and ${ }^{13} \mathrm{C}(75.4 \mathrm{MHz}) \mathrm{NMR}$ data of compound $\mathbf{1}\left(\mathrm{CD}_{3} \mathrm{OD}\right)$

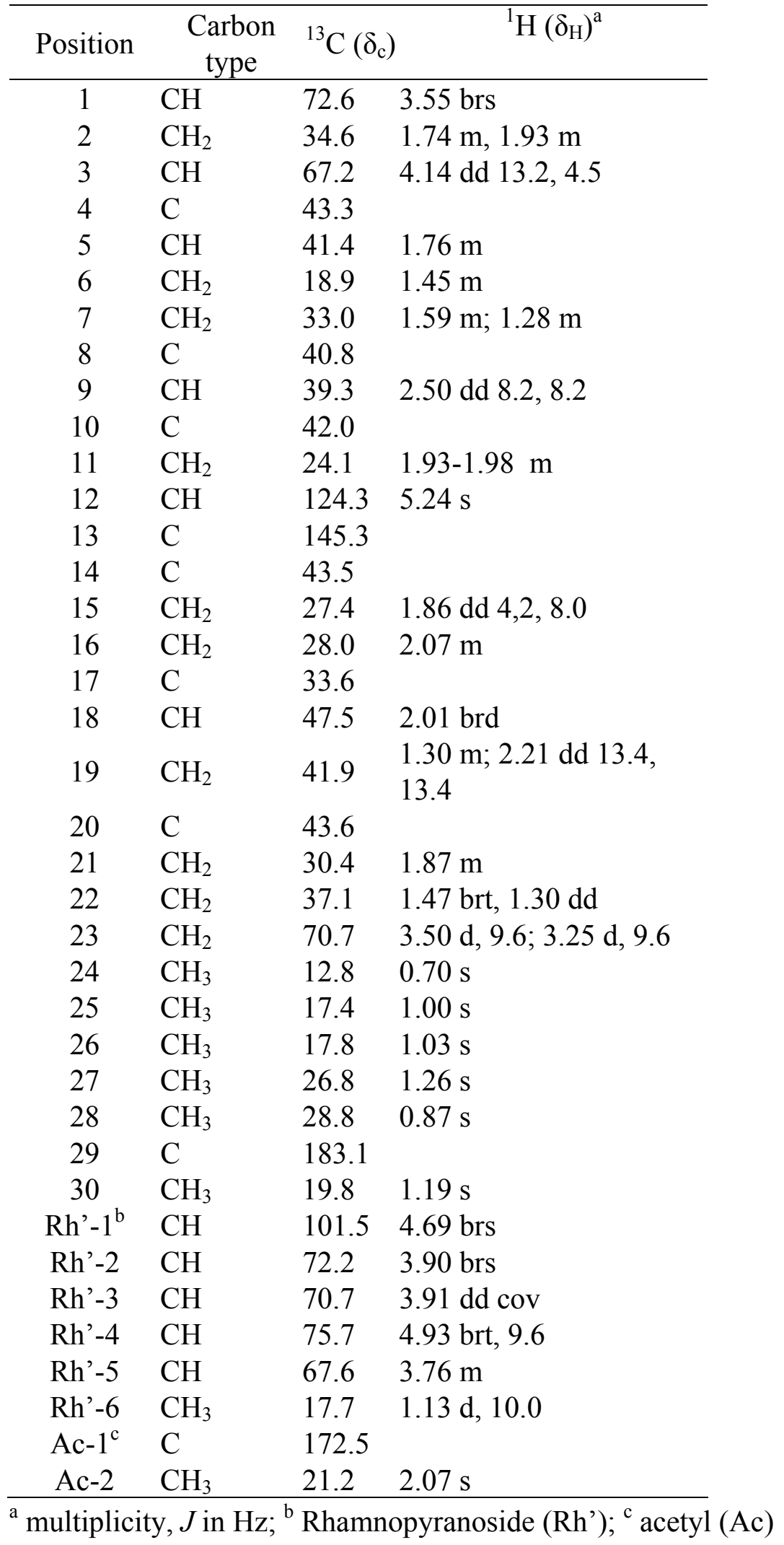


Pentacyclic and tetracyclic triterpenes are well known for their action as molluscides particularly in their monodesmosidic form. ${ }^{8}$ C. molle with its molluscidal constituent, mollic acid, has been recommended for use in rural Africa to control schistosomiasis. ${ }^{9}$ Arjunolic acid and arjungenin, arjunglucoside pentacyclic triterpenes have been isolated from C. molle. ${ }^{10}$ All compounds isolated in this study were subjected to several bioactivity assays. A serial dilution microplate assay using tetrazolium violet as growth indicator, ${ }^{11}$ was used to evaluate the antibacterial activity of the isolated compounds (Table 2) The negative control acetone had no antibacterial activity at the $25 \%$ concentration the bacteria were subjected.

Table 2. Minimum inhibitory concentration (MIC) of isolated compounds ( $\mathrm{mg} / \mathrm{ml})$

\begin{tabular}{ccccc}
\hline & \multicolumn{4}{c}{ Minimum Inhibitory Concentration $(\mathrm{mg} / \mathrm{ml})$} \\
Compound & SA & EF & EC & PA \\
\hline $\mathbf{1}$ & $0.063 \pm 0$ & $>0.25 \pm 0$ & $0.063 \pm 0$ & $>0.25 \pm 0$ \\
$\mathbf{2}$ & $0.031 \pm 0$ & $125 \pm 0$ & $0.063 \pm 0$ & $>250 \pm 0$ \\
$\mathbf{3}$ & $>0.25 \pm 0$ & $>0.25 \pm 0$ & $0.063 \pm 0$ & $>0.25 \pm 0$ \\
Neomycin & $1.9 \times 10^{-3} \pm 0$ & $1.9 \times 10^{-3} \pm 0$ & $3.9 \times 10^{-3}$ & $3.9 \times 10^{-3} \pm 0$ \\
acetone & $>25 \%$ & $>25 \%$ & $>25 \%$ & $>25 \%$ \\
\hline
\end{tabular}

SA Staphylococcus aureus (ATCC 29213), PA Pseudomonas aeruginosa (ATCC 27853), EC Escherichia coli (ATCC 25922), EF Enterococcus faecalis (ATCC 29212).

Compounds 1 and 2 showed inhibition of the Gram-positive $S$. aureus $(0.063 \mathrm{mg} / \mathrm{ml}, 0.031$ $\mathrm{mg} / \mathrm{ml})$ and the Gram-negative E.coli $(0.063 \mathrm{mg} / \mathrm{ml}$ for each compound), whereas E. faecalis and $P$. aeruginosa were resistant to all three isolated compounds, (Table 2). Compound 2 had a slightly lower MIC $(0.031 \mathrm{mg} / \mathrm{ml})$ than the active chloroform fraction $(0.039 \mathrm{mg} / \mathrm{ml})$ indicating that is not responsible for the major antibacterial activity. Compound $\mathbf{1}$ was not active at the highest level tested against the two Gram negative organisms. Compound 1 with MIC (0.063 $\mathrm{mg} / \mathrm{ml})$ greater than that of the chloroform fraction $(0.039 \mathrm{mg} / \mathrm{ml})$ may have acted in synergy with other compounds. From TLC profile examination, compound $\mathbf{3}$ was one the major compound (in terms of quantity) present in the extract.

Apart from this work, there are few data on the antimicrobial potential of the isoprenoid constituents of Combretaceae. Eloff (1998) gathered preliminary data to indicate that crude extracts of $C$. imberbe and $C$. padoides are active against the four most important nosocomial bacterial pathogens. Martini et al (2004) found good antibacterial activity of five flavonoids isolated from $C$. erytrophyllum. The antimicrobial activity of extracts of C. erythrophyllum, ${ }^{12}$ may explain their use in traditional medicine for relieving symptoms that appear to be caused by infective agents e.g. bloody diarrhoea, wounds and conjunctivitis. ${ }^{13}$

Biological assays for antiviral, cytotoxic, and anti-proliferative activity, as well as several yeast-based target oriented assays (e.g. Myc/Max interaction, Tax/Creb interaction) did not indicate any additional biological activities of the three compounds. There was moderate enzyme 
inhibition against $3 \alpha$-hydroxysteroid dehydrogenase observed for $\mathbf{3}$ (data not shown) that might indicate anti-inflammatory activity. As terpenoids related to $\mathbf{1}$ and $\mathbf{2}$ from $C$. imberbe ${ }^{14}$ showed significant inhibitory activities in this assay, an inherent anti-inflammatory activity of this class of compounds of varying intensity, though, can be assumed. Together with the non-cytotoxic effect of the compounds, this supports the use of $C$. padoides and related species in traditional medicine against infections.

\section{Experimental Section}

General Procedures. Column chromatography; silica gel 60M (230-400 mesh, MachereyNagel, Germany), Sephadex LH-20 (Pharmacia Biotech AB, Sweden); TLC: silica gel plates (Sil $\mathrm{G} / \mathrm{UV}_{254}, 0.20 \mathrm{~mm}$, Macherey Nagel, Germany), spots were detected at 254 or $330 \mathrm{~nm}$ and visualized with vanillin $/ \mathrm{H}_{2} \mathrm{SO}_{4}$ spray reagent. Optical rotation, Propol digital automatic polarimeter (Dr. Wolfgang Kernchen GMBH, Germany); IR spectra, IFS55 spectrometer (Bruker, Germany); ${ }^{1} \mathrm{H}$ and ${ }^{13} \mathrm{C}$ NMR spectra, DPX-300, DNMR, DPX-500 (Bruker, Germany), all compounds were measured in $\mathrm{CD}_{3} \mathrm{OD}$ or $\mathrm{CDCl}_{3}$ with reference against TMS (external); ESIMS, triple quadrupole mass spectrometer Quattro (VG Biotech, England); EIMS, 70 eV direct inlet, high resolution with perfluorokerosine as a standard, MAT 95 XL (Finnegan, Germany).

Plant material. The leaves of $C$. padoides were collected from a labelled tree the Lowveld National Botanical Garden in Nelspruit, South Africa. A voucher specimen is deposited in the Botanical Garden Herbarium.

Extraction and isolation. Air-dried and powdered leaves $(500 \mathrm{~g})$ of C. padoides were defatted with hexane and extracted serially and exhaustively by maceration with dichloromethane (DCM), acetone and methanol (MeOH) to afford $12.2 \mathrm{~g}, 11.8 \mathrm{~g}, 18.6 \mathrm{~g}$ and $97.4 \mathrm{~g}$ of $n$-hexane, DCM, acetone and $\mathrm{MeOH}$ soluble extracts, respectively. A portion $(3 \mathrm{~g})$ of the DCM extract, which was the most active extract according to bioautography and MIC $(0.08 \mathrm{mg} / \mathrm{ml})$, was subjected to a liquid-liquid fractionation process that afforded six fractions: chloroform $(1.69 \mathrm{~g})$, water (0.28 g), $n$-butanol (0.78 g), hexane $(0.321 \mathrm{~g}), \mathrm{CCl}_{4}(0.283 \mathrm{~g}), 65 \%$ aqueous $\mathrm{MeOH}(1.25$ g). The chloroform fraction, with good antibacterial activity (MIC $0.037 \mathrm{mg} / \mathrm{ml}$ ), was chromatographed on a $2 \times 30 \mathrm{~cm}$ silica gel 60 gravity column using a stepwise gradient of $n$ hexane and increasing amounts of ethyl acetate (EtOAc) $(20 \%, 800 \mathrm{ml}$ each step), followed by EtOAc with increasing amounts of $\mathrm{MeOH}(10 \% 800 \mathrm{ml}$ each step) ending at $50 \% \mathrm{MeOH}$. Collected fractions were evaporated under vacuum and examined by TLC analysis. Similar fractions were pooled to give seven major fractions $\left(\mathrm{F}_{1}-\mathrm{F}_{7}\right)$ all exhibiting antibacterial activity. Crystals were observed in a tube containing fraction $\mathrm{F}_{4}$ and were washed with a gradient of hexane and acetone to yield $7 \mathrm{mg}$ of compound 2 with an $\mathrm{R}_{\mathrm{f}}$ value of 0.5 in 
ethylacetate/methanol/water $=40: 5.4: 4(\mathrm{EMW})$ as solvent system at $25{ }^{0} \mathrm{C}$. A large quantity of sediment was filtered from fraction $\mathrm{F}_{6}$ and washed with $100 \%$ hexane, followed by hexane/chloroform mixtures with increasing amounts of chloroform $(10 \% 400 \mathrm{ml}$ at each step, up to $50 \%$ ) to give $53 \mathrm{mg}$ of compound 3 with an $\mathrm{R}_{\mathrm{f}}$ value of $0.3 \mathrm{in} \mathrm{EMW}$ at $25^{\circ} \mathrm{C}$. A $150 \mathrm{mg}$ of fraction $\mathrm{F}_{7}$ was further chromatographed on a 3 x $120 \mathrm{~cm}$ Sephadex LH-20 with methanol (1000 $\mathrm{ml}$ ) as eluent. This resulted in $5 \mathrm{mg}$ of $\mathbf{1}$ with an $\mathrm{R}_{\mathrm{f}}$ value of $0.22 \mathrm{in}$ EMW as solvent system at 25 ${ }^{\circ} \mathrm{C}$.

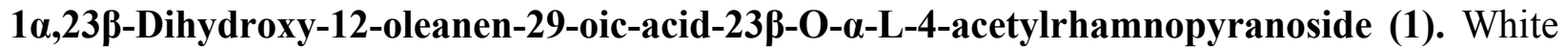
crystals, $[\alpha]_{\mathrm{D}}{ }^{26}+31.39^{\circ}(c 0.15, \mathrm{MeOH})$; IR (film): $v_{\max }=3440,2923,1772,1653,1456 \mathrm{~cm}^{-1}$. ESIMS $1370.8\left[2 \mathrm{M}+\mathrm{NH}_{4}\right]^{+}, 694.8\left[\mathrm{M}+\mathrm{NH}_{4}\right]^{+}$. HRESIMS 675.4100 calculated 675.4108$)[\mathrm{M}-\mathrm{H}]^{-}$ . ${ }^{1} \mathrm{H}$ and ${ }^{13} \mathrm{C}$ NMR: see Table 1.

1,22-Dihydroxy-12-oleanen-30-oic acid (2). Mp, optical rotation, EIMS, IR and ${ }^{13} \mathrm{C}$ NMR data were identical to that reported in the literature. ${ }^{6}$

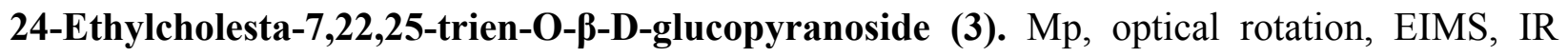
and ${ }^{13} \mathrm{C}$ NMR data were identical to that reported in the literature. ${ }^{7}$

\section{Biological Activity}

Bioautography. Bioautography, ${ }^{15}$ was used in the bioassay-guided isolation of antibacterial compounds and fractions. Developed chromatography plates of $10 \mathrm{mg} / \mathrm{ml}$ extracts and fractions were dried over night and sprayed with a suspension of growing cells of Gram-positive or Gramnegative bacteria, and incubated at $37{ }^{\circ} \mathrm{C}$ in a chamber at $100 \%$ relative humidity for 18 hours. After spraying with $p$-iodonitrotetrazolium salt, clear zones on the chromatogram indicated inhibition of growth after incubating for 1 hour at $37{ }^{\circ} \mathrm{C}$.

Microplate dilution. A 2-fold serial dilution microplate method ${ }^{11}$ was used to determine the minimum inhibitory concentrations (MIC) of fractions and pure compounds against $S$. aureus ATCC 29213, P. aeruginosa ATCC 27853, E. faecalis ATCC 29212 and E. coli ATCC 25922. Tetrazolium violet was used as an indicator of growth.

\section{Acknowledgements}

Colleagues at the HKI department of Biomolecular Chemistry provided spectral data. The German Academic Exchange Service (DAAD), National Research Foundation (NRF), the Faculty of Veterinary Sciences University of Pretoria, and the German Ministry for Education and Research (BMBF, CHN 02/322) provided funds for this work. The South African National Biodiversity Institute gave permission to collect plant material in the Lowveld Botanical Garden. 


\section{References}

1. Eloff, J. N. South African Journal of Science 1999, 5,148.

2. Carr, J. D.; Rogers, C. B. South African Journal of Botany 1997, 53, 173.

3. Rogers, C. B. Phytochemistry 1988, 27, 3217.

4. Pegel, K. H.; Rogers, C. B. J. Chem. Soc., Perkin Trans. 1985, 1, 1711.

5. Roger, C. B.; Subramony, G. Phytochemistry 1988, 27, 531.

6. Nakano, K.; Oase, Y.; Takaishi, Y. Phytochemistry 1997, 46, 1179.

7. Atta-Ur-Rahman, S.; Sumayya, S.; Iqbal, M.; Farzana, A. Phytochemistry 1997, 46, 1721.

8. Marston, B.; Hostettmann, K. Phytochemistry 1985, 24, 639.

9. Rogers, C. B. Phytochemistry 1995, 40, 833.

10. Panzini, I.; Verotta, L.; Rogers, C. B. South African Journal Science 1993, 89, 324.

11. Eloff, J. N. Planta Medica 1998, 64, 711.

12. Martini, N. D.; Eloff, J. N. Journal of Ethnopharmacolgy 1998, 62, 255.

13. Gelfand, M.; Mavi, S.; Drummond, R.; Ndemera, B; The traditional medical practitioner in Zimbabwe, first ed. Mambo press Gweru, 1985, 256.

14. Angeh J. E.; Huang X.; Sattler I.; Swan G. E.; Dahse H.; Härtl A.; Eloff J. N. Journal of Ethnopharmacology In press 2007 http://dx.doi.org/, doi:10.1016/j.jep2006.09.002

15. Begue, W.; Kline R. Journal of Chromatography 1972, 64, 182. 